\title{
Hepatitis C Virus Treatment in Children: A Challenge for Hepatitis C Virus Elimination
}

\author{
Manal H. El-Sayed, MD, PhD ${ }^{1}$ Giuseppe Indolfi, MD² \\ ${ }^{1}$ Department of Pediatrics, Faculty of Medicine, Clinical Research \\ Center, Ain Shams University, Cairo, Egypt \\ 2 Pediatric and Liver Unit, Meyer Children's University Hospital and \\ Department NEUROFARBA, University of Florence, Florence, Italy
}

\begin{abstract}
Address for correspondence Manal H. El-Sayed, MD, PhD, Department of Pediatrics and Clinical Research Center, Faculty of Medicine, Ain Shams University, Cairo 11566, Egypt (e-mail: manalhelsayed@yahoo.co.uk).
\end{abstract}

Semin Liver Dis 2020;40:213-224.

\begin{abstract}
Keywords

- elimination of HCV

- chronic hepatitis C

- children and adolescents

- direct-acting antivirals

Hepatitis $C$ is a global public health threat. The introduction of direct-acting antivirals (DAAs) brings the prospect of curing the 71 million people living with the disease, dramatically changing the landscape of hepatitis $C$. The World Health Organization developed a roadmap for the elimination and cure of hepatitis $C$ by 2030 with a clear goal with measurable targets. However, there is a lack of a well-defined strategy to tackle the hepatitis C virus (HCV) problem in children and adolescents vis-à-vis the adult population. Hepatitis $C$ in children and adolescents can be addressed as part of a national policy for elimination in the whole population, namely macroelimination, or could be fragmented into a microelimination approach targeting the high-risk population groups. Children born to HCV-infected mothers, adolescents who are injecting drugs, migrants, and those suffering from inherited blood diseases are important target populations. After the U.S. Food and Drug Administration approval for the use of DAAs in children aged 3 years and above, evidence from clinical trials and real-world experience was accumulated using brand and generic medicines, with sustained virological response rates exceeding $95 \%$. The evidence created should guide policies on the management of hepatitis $C$ in children and adolescents. There are many challenges in managing HCV in this left-behind marginalized population. The lack of awareness and epidemiological data, consent age, prohibitive prices of medicines, and absence of policies on access to diagnostics, treatment, and linkage to care are among the many barriers to service delivery that should be addressed to achieve the elimination goal by 2030 .
\end{abstract}

Hepatitis C virus (HCV) infection is a major global public health concern. ${ }^{1}$ In 2016, there were an estimated 71 million people living with chronic HCV infection worldwide. ${ }^{2,3}$ This is in addition to approximately 1.75 million new infections per year. ${ }^{2}$ With the advent of direct-acting antivirals (DAAs) in 2013 and the prospect of increasing numbers of cured HCV patients, the World Health Organization (WHO) global health sector strategy on viral hepatitis (2016-2021) defined targets and actions for countries to achieve the goal of eliminating hepatitis $\mathrm{C}$ as a major public health threat by
$2030 .{ }^{4}$ Achieving the elimination goal, however, necessitates a mass scale-up of testing and treatment in both adults and children particularly in the settings with the highest burden of disease. In most countries, the prevalence and burden of HCV infection and its impact on morbidity and the mortality in children and adolescents are essentially unknown. Only one systematic review since 2015 has addressed the prevalence of pediatric HCV infection, with an estimated global prevalence of $0.13 \%$ corresponding to 3.26 million (95\% confidence interval $[\mathrm{CI}]: 2.07-3.90)$ viremic children., ${ }^{5,6}$ published online

June 11,2020
Copyright $\odot 20202020$ by Thieme Medical Publishers, Inc., 333 Seventh Avenue, New York, NY 10001, USA. Tel: +1(212) 760-0888.
DOI https://doi.org/ 10.1055/s-0040-1708812. ISSN 0272-8087. 
$\mathrm{HCV}$ infection infrequently contributes to morbidity during childhood, but the majority of infected children develop chronic HCV, with a lifetime risk of serious liver disease. Cirrhosis is reported in around 1 to $2 \%$ of chronically infected adolescents and children, including decompensation ${ }^{7-14}$ and a few case reports of hepatocellular carcinoma. ${ }^{15}$ In children and adolescents, comorbidities such as hematological diseases with iron overload, obesity, cancer, and viral coinfections (HIV and hepatitis B virus [HBV]) can also accelerate the development of hepatic fibrosis. ${ }^{11-13}$ Moreover, studies have indicated that HCV affects childhood quality of life and behavior, neurocognitive function has been shown to be affected, and families report increased stress that affects family well-being. ${ }^{16,17}$ Little attention has been paid to testing, treatment, and preventive strategies among children and adolescents compared with adults, in part, because until 2017, none of the DAA regimens had been approved for use in people younger than 18 years, and there were major gaps in the evidence to guide pediatric management practices and policies. ${ }^{18}$ Although children under 15 years of age represent an average of $25.8 \%$ of the global population, ranging between approximately $15 \%$ in the most developed countries to more than $40 \%$ in the least developed low-income countries, ${ }^{19}$ and some 1.2 billion adolescents aged 10 to 19 years today make up $16 \%$ of the world's population, ${ }^{20}$ very few national viral hepatitis policies addressed this vulnerable population in their testing, treatment, and preventive strategies. This is despite the high socioeconomic benefits from investing in adolescents' health. It was documented in one study that improving the physical, sexual, and mental health of adolescents aged 10 to 19 years could bring a 10 -fold economic benefit. ${ }^{21}$

Vertical transmission is currently the most important source of pediatric HCV infection, particularly in high-income countries. A retrospective cohort study of pregnant women who delivered between 2006 and 2014 showed that $70 \%$ of HCV-exposed infants were not screened or followedup and therefore were missed. ${ }^{22}$ Furthermore, children whose mothers or other family members are living with $\mathrm{HCV}$ are at an increased risk since the virus can be transmitted through other routes as household contacts.

On the other hand, adolescents remain a vulnerable population for new HCV infections globally with the increasing numbers of injection drug users, young age pregnancies, migration, and displaced populations from conflict zones exposed to violence with no health care coverage or support. More than half of all adolescents globally live in Asia, whereas Sub-Saharan Africa is the region where adolescents make up the greatest proportion of the population, with nearly $23 \%$ of the region's population. ${ }^{20}$ Despite the overall progress in improving access to DAA in the adult population with the availability of affordable generic medicines, many vulnerable groups are being left behind, and particularly children and adolescents in low-resource settings are at a risk.

\section{Elimination of Hepatitis C Virus in Children}

Elimination of HCV infection is defined by the WHO Global Health sector strategy as an $80 \%$ reduction in new HCV infections and a $65 \%$ reduction in HCV mortality by $2030 .{ }^{4}$ It is debated that elimination without the availability of a vaccine has never been attained for any infectious disease. ${ }^{23}$ Elimination of viral hepatitis will require a shifting emphasis from a focus on individual patients to a focus on a coordinated public health approach to interruption of transmission and infection through prevention and treatment. ${ }^{1}$ In the presence of highly effective and safe DAA, the goal should be to reduce the disease burden in every country that requires enhanced rates of diagnosis and treatment, as well as strategies to prevent new infections. Some countries, including Australia, Egypt, Georgia, Iceland among others, have already undertaken broad elimination efforts aimed at the general population. ${ }^{24}$ One of the major gaps in the response to the HCV epidemic, however, remains the lack of reliable epidemiological data in many countries and regions. Data gaps are considerable in some subpopulations including the pediatric population, where there is also lack of awareness regarding the infection. Diagnosis of HCV in children and therefore access to screening is quite challenging due to the asymptomatic nature of the disease and the lack of liver enzyme elevations. ${ }^{25}$ In addition, in countries with low prevalence rates of $\mathrm{HCV}$, the prevalence in infants and children would be quite low, and investments in case finding would be a barrier to identification of infected children. Therefore, risk stratification according to individual country prevalence is important to better define screening policies and ensure access to diagnosis in infants, children, and adolescents. A recent study has shown that in generalized epidemics, the number of tests needed to identify a chronic HCV infection was 2.5 for persons who inject drugs, 2.4 for populations with liver conditions, 2.7 for populations with high-risk health care exposures, and 14.2 for general populations. However, in concentrated epidemics corresponding numbers were $2.8,8.6,5.1$, and 222.2, respectively. Program expansion path curves demonstrated major gains in program efficiency by targeting specific populations. The study concluded that testing strategies can be much more efficient through population prioritization by risk of exposure. ${ }^{26}$

Despite the most recent U.S. Food and Drug Administration (FDA) approval of DAA in children aged 3 years and above (September 2019) and approval for ages 12 years and above since April 2017, access to treatment is still a major concern driven by the prohibitive prices of DAA in some countries and the lack of policies and strategies addressing linkage to care and elimination in the pediatric population. Adolescents also face particular challenges in terms of access to and quality of care, as they have special needs (including for confidentiality) and may not be reached by mechanisms aimed at children and adults. ${ }^{27}$ Furthermore, in countries with the highest burden of $\mathrm{HCV}$ in children and with generic medicines available for use in macroelimination in the adult population, the economics of producing pediatric formulations can be a barrier to access in the younger age groups, particularly in the absence of informing epidemiological data. To date, Egypt is the only country addressing access to the HCV cascade of care on a nationwide basis, with inclusion of school children, 12 years and above and/or weighing more than $35 \mathrm{~kg}$, in a test-and-treat program fully funded by the state and national insurance service. 


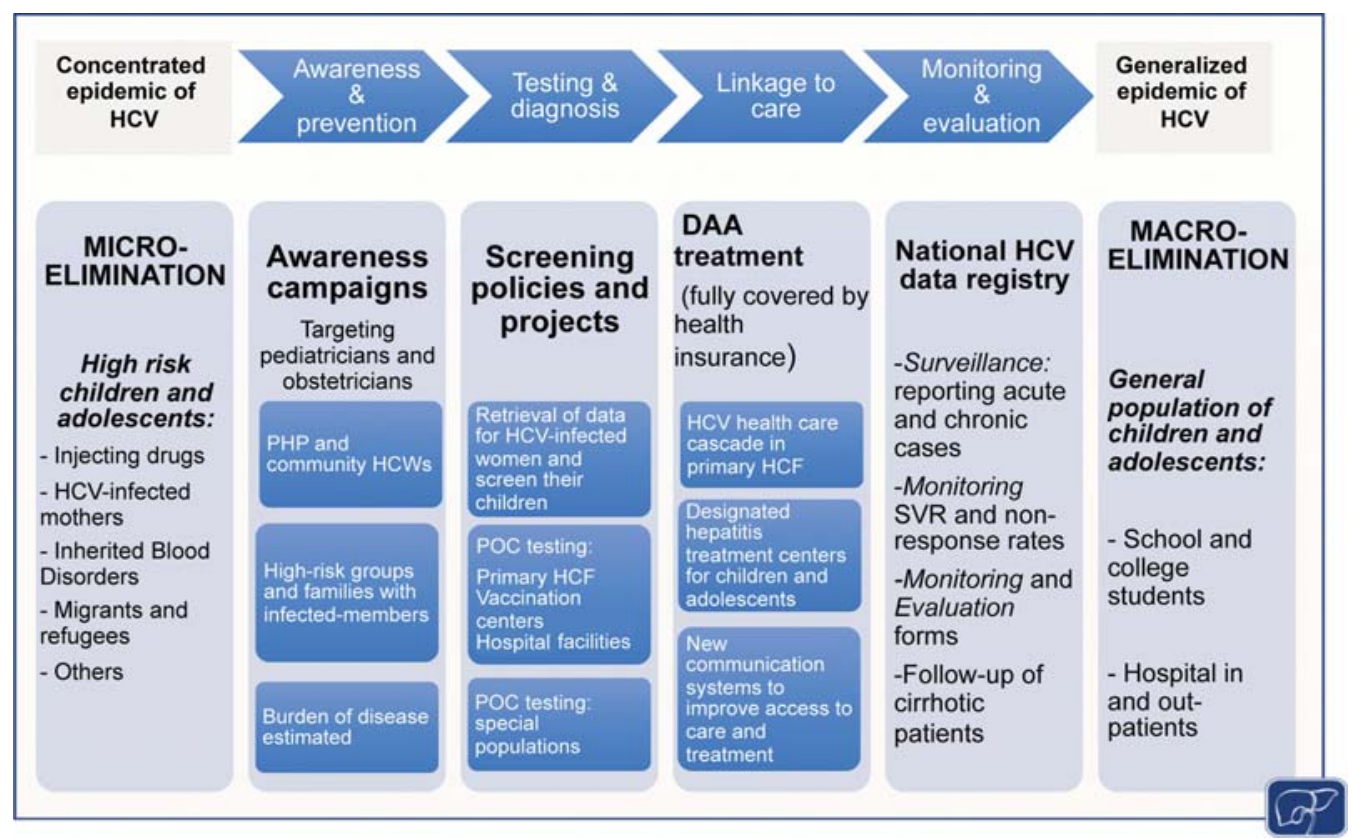

Fig. 1 Simplified cascade of care for micro- and macroelimination of HCV in children and adolescents. HCV, hepatitis C virus; PHP, primary health care physicians; HCWs, health care workers; POC, point of care; HCF, health care facilities; DAA, direct-acting antivirals; SVR, sustained virological response.

A suggested simplified cascade of care for hepatitis C macro- and micro-elimination in children and adolescents is shown in -Fig. 1.

\section{Microelimination in Children and Adolescents}

Elimination of hepatitis $C$ in children and adolescents at high risk of infection is complicated by multiple factors including the large size of the population, consenting age, accessibility to health care services, and cost of implementation. A suggested practical approach is breaking down national elimination goals into smaller goals for individual population segments, for which treatment and prevention interventions can be delivered more quickly and efficiently using targeted methods, a concept known as "microelimination." ${ }^{24}$ Pursuing the microelimination of $\mathrm{HCV}$ approach in the pediatric population means achieving the WHO targets in those at the highest risk of infection (e.g., children infected through mother-to-child transmission or intrafamilial transmission, injecting drug users, those acquiring infection in juvenile penitentiaries and hospital settings, those with inherited blood disorders [IBDs], those coinfected by HIV, migrants, and refugees, among others). Those marginalized subpopulations would benefit most from the microelimination approach, and targeted programs can be designed and tailored to improve access to diagnosis and linkage to care.

\section{Injection Drug Use and Mother-to-Child Transmission} One of the most important consequences of the opioid epidemic has been the rise in HCV infection among persons in the reproductive age group who inject drugs, ${ }^{28,29}$ including pregnant women. Although mother-to-child transmission is recognized as a key source of HCV infection in children, ${ }^{30}$ there are recent concerns of increasing horizontal transmission in adolescents through injecting drug use. ${ }^{31}$ Intravenous drug administration is a significant and increasingly common route of $\mathrm{HCV}$ infection in adolescents and young adults. ${ }^{32}$ This has recently been documented in a United Kingdom study demonstrating that in adolescents, $\mathrm{HCV}$ infection is transmitted by intravenous drug use in $53 \%$, blood products in $24 \%$, and perinatally in $11 \%{ }^{33}$ Other modes of transmission including nosocomial transmissions, percutaneous exposure to blood, and unsafe medical interventions, however, continue to be key risk factors in addition to certain practices such as tattooing and circumcision in resource-limited settings. ${ }^{34}$

In the context of developing microelimination strategies targeting children in specific settings, it may be advisable to consider the possible role of universal screening of pregnant women in those settings. It is noteworthy that teen pregnancy is becoming a global challenge, affecting rich and poor countries alike, but birth rates are highest in resource-poor settings. In Sub-Saharan Africa, the adolescent birth rate is more than twice the global average. ${ }^{35}$ Child marriage is reportedly on the rise for girls in Syria and among Syrian refugee populations, believing marriage will protect them and also ease financial burdens on the family. ${ }^{36}$

Although the risk of vertical transmission of HCV is relatively low (5.8\% [4.2-7.8\%] $)^{31}$ compared with HBV, the public health implications are considerable. Among HIV-HCV coinfected women, the risk of transmission is much higher and estimated to be $10.8 \%$ (7.6-15.2\%). ${ }^{30}$ Unfortunately, most of those HCV infected infants and children are not diagnosed or followed up. The numbers of children with chronic HCV infection will surpass those suffering from chronic HBV given the lack of prevention and control programs for pregnant women and women in child-bearing age with HCV infection 
and the absence of public health approaches for case definition and management of expectant mothers or children. It is noteworthy that globally, the estimated number of women in child-bearing age (15-44 years) who are $\mathrm{HCV}$ viremic is 13.0 million, with 28 countries responsible for $80 \%$ of the infections. ${ }^{6}$ In the United States, the HCV incidence has increased 294\% nationally from 2010 to 2015; acute cases of HCV largely attributed to injection drug use. ${ }^{37}$ A recent report projected nearly 29,000 women with HCV infection giving birth every year, resulting in almost 1,700 infected infants. ${ }^{38}$ The authors noted, though, that only 200 infections in children aged 2 to 13 years are being reported to public health surveillance each year. Continued efforts to ensure that pregnant women have access to transmission prevention services are critical. Suppressing viremia during pregnancy would be expected to prevent HCV transmission. Nonetheless, the newer DAA agents lack sufficient safety data for use during pregnancy, ${ }^{39}$ and pregnancy is currently a contraindication to treatment despite the AASLD/IDSA guidelines' recommendation for universal screening of pregnant women. ${ }^{40}$ Data on DAA in this population are limited to three abstracts on either intentional or accidental exposure during pregnancy in a small number of women. ${ }^{41-43}$ Two studies reported the use of sofosbuvir/ ledipasvir during pregnancy. One study from India included HCV-infected pregnant women who requested treatment during their second or third trimesters to prevent vertical transmission $(n=15) .{ }^{41}$ The other is a phase I trial of sofosbuvir/ledipasvir starting during the second trimester of pregnancy $(n=8)$ from the United States. ${ }^{42}$ The only data available on a pangenotypic combination is a study from Egypt on accidental sofosbuvir/daclatasvir exposure around the time of conception $(n=7)$, all of whom discontinued treatment before week 9 of gestation. No adverse birth outcomes were reported, but one infant tested $\mathrm{HCV}$ positive at 18 months with low viremia. ${ }^{43}$ There are currently no recommendations for the treatment of HCV with DAAs during pregnancy and breastfeeding due to the paucity of sufficient safety data. Ideally, a pan-genotypic, safe, and effective DAA combination would be available to all HCV-pregnant women living with HCV diagnosed by a (cost-effective) universal screening program. ${ }^{44}$

Hepatitis $\mathrm{C}$ testing should be ordered at all routine clinic visits, such as antenatal checks and well-child and vaccination appointments to ensure that those diagnosed receive appropriate treatment. Obstetricians may play a key role by implementing universal testing for $\mathrm{HCV}$ in pregnant women, thereby enhancing the health of mothers and identifying children at risk. This is in addition to integration with HIV, HBV, and syphilis testing during pregnancy. In the meantime, early diagnosis and treatment of $\mathrm{HCV}$ infection in adolescent girls should be considered during their routine checkup or vaccination visits. A unique opportunity, particularly in high-income countries, would be during the routine HPV vaccination recommended by the advisory committee for immunization practices at the age of 11 or 12 years (occasionally starting at age 9 years of age). ${ }^{45}$

It is also important to consider that harm reduction policies, decriminalization, safe-use education campaigns, and removal of stigma related to injecting drug use in adolescents represent an important component for supporting the vulnerable youth and linking them to care. An outreach $\mathrm{HCV}$ test-and-treat program is required to engage adolescents receiving harm reduction and needle syringe exchange services. Concerted efforts are needed to increase the evidence base on interventions that aim to reduce the high burden of HCV in adolescents who inject drugs.

\section{Refugees and Migrants}

Given the growing size of the youth population in the conflict region, as well as migrants and refugees, viral hepatitis needs to be addressed, diagnosed, and managed at an early age. This would prevent complications and transmission of infection and fulfill the WHO's 2030 elimination goal.

Refugees and migrants are marginalized due to risk factors such as HCV prevalence in their country of origin, countries visited during their journey as migrants, and the conditions they experienced during migration; immigrants and refugees are at an elevated risk of being infected with HCV as well as having other health problems. ${ }^{46}$ Migrants often remain unidentified and thus untreated. According to a 2015 review, anti-HCV prevalence among migrants is $1.9 \%$ overall, with higher rates associated with region of origin, particularly Eastern Europe, Asia, and Sub-Saharan Africa. ${ }^{47}$ Today, there are more than 50 million displaced children who need protection, of whom 28 million have been displaced due to wars and extreme poverty. This figure includes the millions of children attempting to flee from the internal strife affecting a dozen countries including Syria, Iraq, Yemen, and South Sudan. The number of children who are suffering due to the conflict and instability in Syria and Iraq alone have reached 14 million. ${ }^{48}$ The total number of HCVinfected children projected in the MENA (Middle East North African) region from verified models is approximately 820,000 out of a population of more than 160 million children below the age of 15 years, with an average infection rate of $0.42 \%{ }^{6}$ This is in addition to an estimated $>1.6$ million HCV-infected women in child-bearing age of $>96$ million in the region with an average prevalence rate of $1.45 \%{ }^{6}$ Regional civil wars, displaced children, health insurance policies, and inequitable insurance coverage are many regional challenges that would impede elimination efforts in this population group.

The WHO recommends screening persons originating from countries with an intermediate $(\geq 2 \%)$ and high $(\geq 5 \%) \mathrm{HCV}$ prevalence. ${ }^{49}$ Migrants and refugees face multiple hurdles in accessing healthcare services, resulting in gaps along all steps of the HCV care continuum. HCV screening uptake and linkage to care, however, can be improved in this population by implementing decentralized community-based screening strategies and working with community-based organizations to overcome cultural and language barriers, ${ }^{50-54}$ or using multidisease testing approaches, whereby $\mathrm{HCV}$ testing is offered as a blood test alongside HBV, HIV, and latent tuberculosis. ${ }^{55} \mathrm{~A}$ randomized controlled trial compared integrated point-of-care testing for HCV, HBV, and HIV in primary care among migrants with individual serological testing and found that testing uptake (98 vs. $62 \%$ ) and linkage to care (90 vs. $83 \%$ ) were higher among point-of-care testing. ${ }^{56}$ In addition, it will 
be necessary to develop screening guidelines and ensure universal access to health care to enhance uptake along the entire HCV cascade of care.

\section{Inherited Blood Disorders}

Chronic infection with the HCV has long been the dominant complication of substitution therapy in patients with IBDs and the cause of anticipated death due to end-stage liver disease. ${ }^{57}$ In industrialized countries, HCV transmission through blood transfusions has been virtually eliminated. In contrast, the blood supply in many low-income countries is poorly controlled. Poor quality screening of blood products in transfusion centers, among other iatrogenic routes, account for the majority of new HCV infections in resource-limited countries. ${ }^{34}$ Blood transfusion safety is still a concern, especially in low- and middle-income countries, where the prevalence of transfusion-transmissible infections among blood donors is high, but quality and coverage of blood screening is inadequate. The 2016 WHO Global Status Report on Blood Safety and Availability reported that in low- and middle-income countries, up to $67 \%$ of all transfusions are for children under the age of 5 years. ${ }^{58} \mathrm{~A}$ spontaneous HCV clearance rate of 28 to $42 \%$, however, has been reported among thalassemic and hemophilic patients in the West. ${ }^{59,60}$

The prevalence of anti-HCV seropositivity among thalassemia patients has been reported to be 2.7 to $97 \%$ across countries in an early report. ${ }^{61}$ In the West, cohorts of HCV infected thalassemic patients are mainly comprise adults, of whom $80 \%$ acquired the infection before $1990,{ }^{62}$ whereas in the Middle East and Asia, the same is true for many children or young adults (10-40\% of all patients) who acquired the infection in the last decades, resulting in the development of chronic liver disease. ${ }^{63-70}$

DAA treatment of hepatitis $C$ as part of a microelimination program targeting IBD is an effective intervention aiming to prevent transmission of $\mathrm{HCV}$ in the general population. ${ }^{46}$ Many recent studies suggest that individuals with IBD may safely and successfully be treated for HCV with the DAA therapy. ${ }^{71}$ In five recent studies investigating the DAA treatment in 254 hemophiliacs and von Willebrand disease patients, of whom 51 were cirrhotic, 243 were cured of hepatitis $C^{71-75}$ Other reports in thalassemic patients documented cure of 401 out of the 420 recruited patients with various genotypes and degrees of fibrosis. $^{76-79}$ The average success HCV cure rate in patients with IBD was 95\% in published studies. The current European Association for the Study of the Liver Clinical Practice Guidelines recommend interferon-free regimens for the treatment of HCV infection in patients with hemoglobinopathies, as DAA have provided $>90 \%$ rates of cure, irrespective of HCV genotype or history of previous antiviral therapy. ${ }^{80}$ The use of DAA in the treatment of HCV-infected children and adolescents with IBD should be implemented for microelimination in this population, particularly in resource-limited settings with high prevalence rates. This approach would prevent horizontal and nosocomial transmissions in this high-risk population and avert early liverrelated morbidity and mortality.

\section{Evidence on the Use of DAA for Adolescents and Children with Chronic HCV Infection}

The drug regimens currently approved for use in adolescents and children with chronic HCV infection by the FDA are summarized in -Table $\mathbf{1}$. - Table 2 reports the ongoing pediatric trials with the second-generation DAA regimens.

\section{Sofosbuvir/Ledipasvir}

The fixed-dose combination of sofosbuvir/ledipasvir is approved by the FDA for the treatment of children and adolescents (3-17 years of age) with chronic HCV genotype 1, 4, 5, or 6 infection (- Table 1)..$^{40,81,82}$

A large phase II and III, open-label, multicenter, multicohort study evaluated the safety and the efficacy of sofosbuvir (a potent NS5B polymerase inhibitor) and ledipasvir (an NS5A inhibitor). ${ }^{83-85}$

Table 1 Age and genotypic indications provided by the U.S Food and Drug Administration on the use of the direct-acting antiviral regimens approved for the treatment of chronic hepatitis $C$ virus infection in adolescents and children

\begin{tabular}{|c|c|c|c|}
\hline Regimen & $\begin{array}{l}\text { GT and duration } \\
\text { of treatment }\end{array}$ & Formulations & Doses by age \\
\hline $\begin{array}{l}\text { Sofosbuvir/ } \\
\text { ledipasvir }\end{array}$ & $\begin{array}{l}\text { GT } 1,4,5,6: 12 \mathrm{wk} \\
\text { GT 1, treatment-experienced } \\
\text { (IFN-based therapy) } \\
\text { or cirrhosis: } 24 \mathrm{wk}\end{array}$ & $\begin{array}{l}\text { Tablet (FDC) } 400 / 90 \mathrm{mg} \\
\text { Tablet (FDC) } 100 / 22.5 \mathrm{mg} \\
\text { Packet of granules } \\
50 / 11.25 \mathrm{mg}\end{array}$ & $\begin{array}{l}12-17 \text { y or weighing } \geq 35 \mathrm{~kg}: 400 / 90 \mathrm{mg} / \mathrm{d} \\
6-11 \text { y: } 200 / 45 \mathrm{mg} / \mathrm{d} \\
3-5 \mathrm{y}: 200 / 45 \mathrm{mg} / \mathrm{d} \text { if } \geq 17 \mathrm{~kg} \\
150 / 33.75 \mathrm{mg} / \mathrm{d} \text { if }<17 \mathrm{~kg}\end{array}$ \\
\hline $\begin{array}{l}\text { Sofosbuvir } \\
+ \text { ribavirin }\end{array}$ & $\begin{array}{l}\text { GT 2: } 12 \text { wk } \\
\text { GT 3: } 24 \text { wk }\end{array}$ & $\begin{array}{l}\text { Sofosbuvir } \\
\text { Tablet } 400 \mathrm{mg} \\
\text { Tablet } 100 \mathrm{mg} \\
\text { Capsules } 50 \mathrm{mg} \text { (granules) }\end{array}$ & $\begin{array}{l}\text { Sofosbuvir } \\
12-17 \text { y or weighing } \geq 35 \mathrm{~kg}: 400 \mathrm{mg} / \mathrm{d} \\
6-11 \mathrm{y}: 200 \mathrm{mg} / \mathrm{d} \\
3-5 \mathrm{y}: 200 \text { if } \geq 17 \mathrm{~kg} ; 150 \mathrm{mg} / \mathrm{d} \text { if }<17 \mathrm{~kg} \\
\text { Ribavirin } \\
15 \mathrm{mg} / \mathrm{kg} / \mathrm{d} \text { in two divided doses }\end{array}$ \\
\hline $\begin{array}{l}\text { Glecaprevir/ } \\
\text { pibrentasvir }\end{array}$ & $\begin{array}{l}\text { All GTs: } 8 \text { wk } \\
\text { All GTs with cirrhosis: } 12 \text { wk } \\
\text { GT 3, treatment-experienced } \\
\text { (IFN-based therapy): } 16 \text { wk }\end{array}$ & Tablet (FDC) $100 / 40$ mg/day & $12-17$ y or weighing $\geq 45 \mathrm{~kg}: 300 / 120 \mathrm{mg} / \mathrm{d}$ \\
\hline
\end{tabular}

Abbreviations: FDC, fixed-dose combination; GT, genotype; IFN, interferon. 
Table 2 Ongoing pediatric trials with second-generation direct-acting antiviral regimens

\begin{tabular}{|l|l|l|}
\hline Drugs & $\begin{array}{l}\text { Clinicaltrial.gov } \\
\text { accession number }\end{array}$ & Main characteristic of the combination \\
\hline Sofosbuvir/velpatasvir & NCT03022981 & Pangenotypic regimen \\
\hline Glecaprevir/pibrentasvir & NCT03067129 & $\begin{array}{l}\text { Pangenotypic regimen; this combination is safe and } \\
\text { effective in patients with advanced renal disease }\end{array}$ \\
\hline $\begin{array}{l}\text { Sofosbuvir/velpatasvir/ } \\
\text { voxilaprevir }\end{array}$ & NCT03820258 & $\begin{array}{l}\text { Pangenotypic regimen for patients who have experienced } \\
\text { treatment failure with DAA therapy; treatment for } 8 \text { wk for } \\
\text { almost all the patients treated }\end{array}$ \\
\hline Elbasvir/grazoprevir & NCT03379506 & $\begin{array}{l}\text { Agents are completely hepatically metabolized, and } \\
\text { pharmacokinetic data in adults showed them to be safe in } \\
\text { patients with advanced renal disease including those on hemodialysis }\end{array}$ \\
\hline
\end{tabular}

\section{Adolescents}

Sofosbuvir and ledipasvir were used for 12 weeks (-Table 3). ${ }^{85}$ The first 10 adolescents underwent separate intensive pharmacokinetic evaluations of the concentrations of sofosbuvir and ledipasvir. The adult dosing resulted in comparable plasma exposures in adolescents than those found in phase II and III clinical trials in adults with chronic hepatitis $\mathrm{C}(\mathrm{CHC})$. The efficacy of the combination was high (SVR12 [sustained virological response at week 12 posttreatment] 98\%, intention-to-treat analysis). Of the 100 patients who initiated treatment, 99 completed and 1 discontinued the treatment, and of those who completed the treatment, 1 did not attend the posttreatment follow-up visits after having achieved end of treatment response. The efficacy was similar among treatment-naïve (78/80; SVR12: 98\%;
95\% CI: 91-100\%) and treatment-experienced patients (20/20; SVR12: 100\%; 95\% CI: 83-99\%). The only patient with cirrhosis was treatment-naïve, received 12 weeks of therapy, and achieved SVR12. The treatment was well tolerated. No serious or grade 3/4 adverse event was reported, and no patient discontinued treatment due to an adverse event. ${ }^{85}$

\section{Children Younger Than 12 Years}

Results of the same association are available for children aged 6 to 11 years ${ }^{83}$ and for those aged 3 to 5 years ( - Table 3 ) ${ }^{84}$ Treatment duration was 12 weeks for all except one patient with HCV genotype 1 infection who was treatment-experienced and cirrhotic and two patients with HCV genotype 3 infection who received 24 weeks of therapy. ${ }^{2}$ The pharmacokinetic analyses showed that the "half strength" dosing

Table 3 Summary of the pediatric studies on different combinations of direct-acting antivirals

\begin{tabular}{|c|c|c|c|c|c|}
\hline Drug regimen & $\begin{array}{l}\text { Age range } \\
\text { (years) }\end{array}$ & $\begin{array}{l}\text { Sample } \\
\text { size }\end{array}$ & Genotype(s) & Drug doses & $\begin{array}{l}\text { Number of patients } \\
\text { with SVR12 (\%) }\end{array}$ \\
\hline \multirow{3}{*}{$\begin{array}{l}\text { Sofosbuvir/ } \\
\text { ledipasvir }\end{array}$} & $12-17^{85}$ & 100 & 1 & $400 / 90 \mathrm{mg}$ & $98 / 100(98 \%)$ \\
\hline & $6-11^{83}$ & 92 & $1,3,4$ & $200 / 45 \mathrm{mg}$ & $91 / 92$ (99\%) \\
\hline & $3-5^{84}$ & 34 & 1,4 & $\begin{array}{l}\text { if } \geq 17 \mathrm{~kg}: 200 / 45 \mathrm{mg} \\
\text { if }<17 \mathrm{~kg}: 150 / 33.75 \mathrm{mg}\end{array}$ & $33 / 34(97 \%)$ \\
\hline \multirow[t]{2}{*}{$\begin{array}{l}\text { Sofosbuvir } \\
\text { plus ribavirin }\end{array}$} & $12-17^{94}$ & 52 & 2,3 & $\begin{array}{l}\text { Sofosbuvir } 400 \mathrm{mg} \\
\text { Ribavirin } 15 \mathrm{mg} / \mathrm{kg} \text { in two divided doses }\end{array}$ & $51 / 52(98 \%)$ \\
\hline & $3-11^{95}$ & 54 & 2,3 & $\begin{array}{l}\text { Sofosbuvir } \\
\text { 6-11 years: } 200 \mathrm{mg} \\
\text { 3-5 y: } 200 \mathrm{mg} \text { if } \geq 17 \mathrm{~kg} ; 150 \mathrm{mg} \text { if }<17 \mathrm{~kg} \\
\text { Ribavirin } 15 \mathrm{mg} / \mathrm{kg} \text { in two divided doses }\end{array}$ & $53 / 54(98 \%)$ \\
\hline $\begin{array}{l}\text { Glecaprevir/ } \\
\text { pibrentasvir }\end{array}$ & $12-17^{98}$ & 47 & $1,2,3,4$ & $300 / 120 \mathrm{mg}$ & $47 / 47(100)$ \\
\hline $\begin{array}{l}\text { Ombitasvir/ } \\
\text { paritaprevir/ } \\
\text { ritonavir } \\
\pm \text { dasabuvir } \\
\pm \text { ribavirin }\end{array}$ & $12-17^{97}$ & 38 & 1,4 & $\begin{array}{l}25 \mathrm{mg} / 150 \mathrm{mg} / 100 \mathrm{mg} \text { once daily } \\
\text { Dasabuvir } 250 \mathrm{mg} \text { twice daily } \\
\text { Ribavirin } 15 \mathrm{mg} / \mathrm{kg} \text { in two divided doses }\end{array}$ & $38 / 38(100)$ \\
\hline \multirow{5}{*}{$\begin{array}{l}\text { Sofosbuvir } \\
\text { plus } \\
\text { daclatasvir }\end{array}$} & $15-17^{99}$ & 13 & 4 & \multirow{5}{*}{$\begin{array}{l}\text { Sofosbuvir } 200 \mathrm{mg} \\
\text { Daclatasvir } 60 \mathrm{mg}\end{array}$} & $13 / 13(100 \%)$ \\
\hline & $13-17^{103}$ & 10 & 4 & & $10 / 10(100)$ \\
\hline & $12-17^{100}$ & 30 & 4 & & $29 / 29(100)$ \\
\hline & $8-17^{102}$ & 40 & 1,4 & & $39 / 39(100)$ \\
\hline & $7-13^{101}$ & 14 & 3 & & $14 / 14(100)$ \\
\hline
\end{tabular}

Abbreviation: SVR12, sustained virological response at week 12 posttreatment. 
resulted in plasma concentration generally within the range of those observed in adults. ${ }^{86}$ Ninety-nine percent (91/92; 95\% CI: 94-100\%) of the children achieved SVR12. One cirrhotic patient with HCV genotype 1a relapsed at followup week 4 visit. The treatment was well tolerated; no grade $3 / 4$ adverse event was reported, and no patient discontinued the treatment due to an adverse event. One serious adverse event (a dental abscess with abdominal pain and gastroenteritis) was reported that was not considered drug-related. ${ }^{83}$

Of the children, 99\% between 3 and 5 years treated with weight-based doses of combined ledipasvir-sofosbuvir as granules achieved SVR12 (33/34; 95\% CI: 85-100\%). The only patient who did not achieve SVR12 was 3 years old and discontinued treatment after 5 days due to "abnormal drug taste." The treatment was well tolerated; no grade 3/4 adverse event was reported, and no patient discontinued the treatment due to an adverse event. ${ }^{84}$

\section{Real-World Data}

The results of the registration study have been recently confirmed in several real-word studies using the same drug doses and treatment durations. ${ }^{87-90}$ Three different studies recently reported the efficacy and safety of sofosbuvir/ledipasvir used for 8 weeks of treatment in adolescents with chronic HCV infection. Eight weeks of treatment resulted in comparable efficacy and safety independently of HCV genotype. ${ }^{91-93}$

\section{Sofosbuvir and Ribavirin}

The combination of sofosbuvir and ribavirin is approved by the FDA for the treatment of children and adolescents ( $3-17$ years of age) with chronic HCV genotypes 2 or 3 infection ( - Table 1 ). The recommended treatment duration is 12 weeks for genotype 2 and 24 weeks for genotype $3 .^{40,81,82}$ A large phase II and III, open-label, multicenter, multicohort, single-arm study evaluated the safety and the efficacy of sofosbuvir and ribavirin. ${ }^{94,95}$

\section{Adolescents}

Sofosbuvir and ribavirin were used for adolescents (aged between 12 and 17 years or weighing more than $35 \mathrm{~kg}$ ) with chronic HCV genotype 2 or 3 infection for 12 or 24 weeks, respectively (-Table 3). ${ }^{94}$ Pharmacokinetic evaluations of the concentrations of sofosbuvir showed that $400 \mathrm{mg}$ per day provided plasma exposures comparable with those observed in adults from phase II and III studies. The combination showed high efficacy and a good safety profile, and SVR12 was 98\% (95\% CI: 90-100\%; intention-to-treat analysis) overall, $100 \%$ (95\% CI: $75-100 \%$ ) for genotype 2, and $97 \%$ (95\% CI: 87-100\%) for genotype 3. All the nine treatmentexperienced patients achieved SVR12 (100\%; 95\% CI: 66$100 \%)$. The single patient who did not achieve SVR12 achieved end of treatment response and SVR4 (HCV RNA negative 4 weeks after the end of treatment) and then was lost to follow-up. Treatment was well tolerated. No serious or grade 3/4 adverse event related to the study drug was reported, and no patient discontinued treatment due to an adverse event.

\section{Children Younger Than 12 Years}

Results of the same association are available for 41 children aged 6 to 11 years and for 13 children aged 3 to 5 years (-Table 3). ${ }^{95}$ The pharmacokinetic analyses conducted in each age group confirmed the appropriateness of sofosbuvir doses. Of the children, 98\% (53/54; 95\% CI: 90-100\%) achieved SVR12. The only patient who did not achieve SVR12 was 4 years old and discontinued treatment after 3 days due to "abnormal drug taste." The treatment was well tolerated; no grade 3/4 adverse event was reported. One serious adverse event (a 3-year-old patient with accidental ribavirin overdose requiring hospitalization for monitoring) was reported. This child completed treatment and achieved SVR12. ${ }^{95}$

\section{Real-World Data}

The results of the sofosbuvir and ribavirin registration study have been confirmed in an open-labeled uncontrolled study from Pakistan. In this study, 35 children with a mean age of $10.24 \pm 2.80$ years were enrolled and treated for 24 weeks to determine the safety and efficacy of sofosbuvir and ribavirin. ${ }^{96}$ Interestingly, 27 (77.1\%) were infected by HCV genotype 3 and 6 (17.1\%; two untypeable) by genotype 1 . SVR12 was achieved by all the patients with genotype 1 infection and by $26 / 27$ (96.3\%) of those with HCV genotype 3. The treatment was well tolerated in most patients. No serious adverse event was reported. Headache was observed in eight children (22.86\%). One patient stopped the therapy at treatment week 8 for severe headache and achieved SVR12, and constipation was observed in one patient.

\section{Ombitasvir/Paritaprevir/ \\ Ritonavir \pm Dasabuvir \pm Ribavirin}

The combination of ombitasvir/paritaprevir/ritonavir with or without dasabuvir, with or without ribavirin is not yet approved for the treatment of children and adolescents with chronic HCV infection.

The ZIRCON open-label, multicenter study (NCT 02486406) is currently exploring the safety and efficacy of this association in children aged 3 to 17 years, with HCV genotype 1 or 4 infection, treatment-naive and treatment-experienced, with or without compensated cirrhosis. In this study, the fixed-dose combination of ombitasvir/paritaprevir/ritonavir was used with dasabuvir for patients with genotype 1 infection and with ribavirin for those with genotype $1 \mathrm{a}$ and 4 infections. The duration of treatment was 12 weeks for all the patients enrolled except for those with genotype $1 \mathrm{a}$ infection or with compensated cirrhosis who were treated for 24 weeks. Preliminary results were presented for the 12- to 17-year age cohort. $^{97}$

\section{Adolescents}

Thirty-eight adolescents were enrolled in this study. ${ }^{97}$ Pharmacokinetic evaluations showed that the exposures to the four drugs in the 12 adolescents studied were comparable with exposures seen in adults. The combination showed excellent efficacy and a good safety profile. SVR12 was $100 \%$ and therefore independent of genotype, treatment 
history, and stage of liver disease. No adverse event led to discontinuation of study drugs.

\section{Glecaprevir/Pibrentasvir}

The combination of glecaprevir/pibrentasvir is approved by the FDA for the treatment of adolescents with chronic HCV infection ( - Table $\mathbf{1})$.

The DORA open-label, multicenter study is currently exploring the safety and efficacy of this association in children aged 3 to 17 years, independently of HCV genotype, treatment-naive and treatment-experienced, with or without compensated cirrhosis. In this study the duration of treatment with the fixed-dose combination of glecaprevir/pibrentasvir was 8 weeks for all the patients enrolled except for those with compensated cirrhosis who were treated for 12 weeks and those treatment-experienced with HCV genotype 3 infection who were treated for 16 weeks. Preliminary results were presented for the 12 to 17 age cohort. ${ }^{98}$

\section{Adolescents}

Forty-seven adolescents were enrolled in this study (-Table 3). Pharmacokinetic evaluations showed that the exposures to the adult dose were comparable with exposures seen in adults. SVR12 was $100 \%$. No patients had virological nonresponse, breakthrough or relapse. Treatment was well tolerated. No serious adverse event was reported and no patient discontinued treatment due to an adverse event. ${ }^{98}$

\section{Sofosbuvir + Daclatasvir \pm Ribavirin}

The combination of sofosbuvir + daclatasvir with or without ribavirin is not approved for the treatment of children and adolescents with chronic HCV infection.

In 2017, for the first time, the preliminary results of an Egyptian study on the use of sofosbuvir $400 \mathrm{mg}$ and daclatasvir $60 \mathrm{mg}$ once daily have been presented ( - Table 3). ${ }^{99}$ Thirteen adolescents aged between 15 and 17 years with HCV genotype 4 infection received 12 weeks of treatment. Ribavirin was used in the four patients with cirrhosis, and SVR 12 was $100 \%$. No serious adverse event was reported, whereas mild adverse events were noted in the form of mild headache, dizziness, itching, and ribavirin-induced hemoglobin reduction $(<1 \mathrm{~g} / \mathrm{dL})$. The adult dosing resulted in comparable plasma exposures in adolescents than those found in phase II and III clinical trials in adults with CHC (unpublished data, Manal H. El-Sayed, MD, PhD, 2019). Following this study, many others confirmed the efficacy and the safety of this combination for adolescents and children. ${ }^{100-102}$

A recent pilot study explored the efficacy of a shortened 8week duration of sofosbuvir and daclatasvir in a cohort of 10 consecutive adolescents. All patients (10/10 (100\% (CI: 72.25$100 \%$ ) achieved SRV with good tolerability and no serious adverse events. ${ }^{103}$

\section{Challenges toward the Elimination of $\mathrm{HCV}$ in Children}

To achieve WHO's elimination goal and targets by 2030, it is pivotal to understand the current challenges associated with
HCV elimination worldwide and undertake strategic efforts to overcome these challenges.

In the absence of a vaccine, HCV treatment is central to infection control. An HCV vaccine would be an important public health tool to interrupt and control HCV spread and to protect high-risk populations such as people who inject drugs. The first prophylactic randomized, placebocontrolled, phase I/II trial (NCT01436357) of a prime-boost vaccine to prevent chronic $\mathrm{HCV}$ infection in an at-risk population demonstrated the feasibility of conducting rigorous vaccine research in people who inject drugs. The regimen elicited robust immune responses without evident safety concerns but did not provide protection against chronic HCV infection. ${ }^{104}$

In recent years, the new DAA combinations have revolutionized the treatment of CHC globally. These treatments have excellent efficacy and safety in both adults and children, with more than 95\% SVR rates. The few side effects and the short treatment durations (as short as 8 weeks) have dramatically improved patient adherence relative to the previous standard of care: pegylated interferon and ribavirin. Although an increasing number of DAA have gained approval for adults since 2011 worldwide, the expansion of DAA treatment to adolescents and children and access to DAA for these populations remains slow and limited due to various factors. First, the degree of awareness regarding chronic $\mathrm{HCV}$ infection in children and adolescents is low. Chronic HCV infection in childhood has usually and inappropriately been considered a mild disease. The outcome of the infection beyond the pediatric age, as well as the social stigma related to the infection and the burden of the extrahepatic manifestations, has never been adequately evaluated. Overall, the need for general proactive screening, as well as through the use of simple, adolescent-friendly testing, is underperceived. Poor linkage to care is a key barrier to treatment for adults as well as for adolescents and children. Newer and further highly effective, safe, and simple treatment options are required to increase the treatment uptake in the HCV pediatric population. The pangenotypic regimen sofosbuvir/ velpatasvir, glecaprevir/pibrentasvir, and sofosbuvir/velpatasvir/voxilaprevir can simplify the treatment and satisfy the clinically unmet needs in patients with cirrhosis and prior treatment failure. However, DAA regimens are still largely unaffordable to many patients worldwide. Wider medical reimbursement coverage is therefore needed to improve the affordability of DAA regimens, which will enhance treatment uptake. Global efforts are underway to accelerate the development and introduction of pediatric formulations. ${ }^{105}$ These efforts rely on coordinated and well-funded actions by policy-makers, researchers, industry, regulators, and other relevant stakeholders. ${ }^{18}$

Children and adolescents need to be included in a country's age-stratified national population-based serosurveys and should be part of the global, regional, and national data reporting systems and strategies for control of viral hepatitis. Moreover, long-term follow-up data systems are required to monitor the progression of liver disease in children. Integration of HCV with other childhood infectious disease surveillance health information systems can also capture new 
infections and identify risk factors, therefore guiding national and preventive strategies. It is critical to simplify the cascade of diagnosis and assessment through point-of-care test and treat programs with noninvasive assessment to stage liver disease. This would increase the number of diagnosed and treated children and adolescents particularly in the high-risk populations. While actively engaging adolescents, preventive interventions can be delivered in educational settings, which provide an opportune platform to deliver information relating to HCV and the behaviors linked to the transmission of infection. With the fast-growing newer technologies and communication systems, innovations can be tailored for delivery of the services to children and adolescents and improve access to care and treatment.

This requires key stakeholders collaboration across different sectors including governments, research institutes, HCV associations and consortia, media, information and technology experts, civil society, and pharmaceutical companies, as well as pediatric and obstetric health care professionals to integrate all resources to combat and eliminate HCV. International collaborative efforts are required for the development of robust HCV data registries on diagnosed, treated, and cured children and adolescents. Models of care in this key population particularly in high burden settings can guide global and national policies and practices on prevention, diagnosis, and linkage to treatment. Elimination of HCV can eventually be achieved with the global commitment for universal health coverage through integrated policies and programs leaving no one behind.

\section{Conflict of Interest}

The authors report that they have nothing to disclose.

\section{References}

1 Cooke GS, Andrieux-Meyer I, Applegate TL, et al; Lancet Gastroenterology \& Hepatology Commissioners. Accelerating the elimination of viral hepatitis: a Lancet Gastroenterology \& Hepatology Commission. Lancet Gastroenterol Hepatol 2019;4(02):135-184

2 World Health Organization. Global Hepatitis Report, 2017. Geneva: World Health Organization; 2017

3 Polaris Observatory HCV Collaborators. Global prevalence and genotype distribution of hepatitis $C$ virus infection in 2015: a modelling study. Lancet Gastroenterol Hepatol 2017;2(03): 161-176

4 World Health Organization. Global health sector strategy on viral hepatitis, 2016-2021: towards ending viral hepatitis. 2016. Available at: http://apps.who.int/iris/bitstream/10665/246177/ 1/WHO-HIV-2016.06-eng.pdf. Accessed October 16, 2019

5 Schmelzer J, Dugan E, Blach S, et al. Global prevalence of hepatitis C virus infection infection in children in 2018: a modelling study. Gastroenterol Hepatol 2020 (e-pub ahead of print) . Doi: 10.1016/ S2468-1253(19)30385-1

6 Razavi H, El-Sayed M. Updated Global Estimate of HCV Infection in the Pediatric Population. Available at: http://cdafound.org/content/Downloads/Pediatric\%20Prevalence\%20161201.pdf. Accessed October 18, 2019

7 Bortolotti F, Verucchi G, Cammà C, et al; Italian Observatory for HCV Infection and Hepatitis C in Children. Long-term course of chronic hepatitis $C$ in children: from viral clearance to end-stage liver disease. Gastroenterology 2008;134(07):1900-1907
8 European Paediatric Hepatitis C Virus Network. Three broad modalities in the natural history of vertically acquired hepatitis C virus infection. Clin Infect Dis 2005;41(01):45-51

9 Jara P, Resti M, Hierro L, et al. Chronic hepatitis C virus infection in childhood: clinical patterns and evolution in 224 white children. Clin Infect Dis 2003;36(03):275-280

10 Iorio R, Giannattasio A, Sepe A, Terracciano LM, Vecchione R, Vegnente A. Chronic hepatitis $C$ in childhood: an 18-year experience. Clin Infect Dis 2005;41(10):1431-1437

11 Indolfi G, Guido M, Azzari C, Resti M. Histopathology of hepatitis $\mathrm{C}$ in children, a systematic review: implications for treatment. Expert Rev Anti Infect Ther 2015;13(10):1225-1235

12 Goodman ZD, Makhlouf HR, Liu L, et al. Pathology of chronic hepatitis $C$ in children: liver biopsy findings in the Peds-C Trial. Hepatology 2008;47(03):836-843

13 Guido M, Bortolotti F, Leandro G, et al. Fibrosis in chronic hepatitis $C$ acquired in infancy: is it only a matter of time? Am J Gastroenterol 2003;98(03):660-663

14 Castellino S, Lensing S, Riely C, et al. The epidemiology of chronic hepatitis C infection in survivors of childhood cancer: an update of the St Jude Children's Research Hospital hepatitis C seropositive cohort. Blood 2004;103(07):2460-2466

15 González-Peralta RP, Langham MR Jr, Andres JM, et al. Hepatocellular carcinoma in 2 young adolescents with chronic hepatitis C. J Pediatr Gastroenterol Nutr 2009;48(05):630-635

16 El-Shabrawi MH, Kamal NM. Burden of pediatric hepatitis C. World J Gastroenterol 2013;19(44):7880-7888

17 Rodrigue JR, Balistreri W, Haber B, et al. Impact of hepatitis C virus infection on children and their caregivers: quality of life, cognitive, and emotional outcomes. J Pediatr Gastroenterol Nutr 2009;48(03):341-347

18 Indolfi G, Easterbrook P, Dusheiko G, et al. Hepatitis C virus infection in children and adolescents. Lancet Gastroenterol Hepatol 2019;4(06):477-487

19 The World Bank. Population ages 0-14 (\% of total population). Available at: https://data.worldbank.org/indicator/SP.POP.0014. TO.ZS. Accessed October 2019

20 UNICEF. Adolescent demographics. Available at: https://data. unicef.org/topic/adolescents/demographics/\#status. Accessed October 2019

21 Sheehan P, Sweeny K, Rasmussen B, et al. Building the foundations for sustainable development: a case for global investment in the capabilities of adolescents. Lancet 2017;390 (10104):1792-1806

22 Chappell CA, Hillier SL, Crowe D, Meyn LA, Bogen DL, Krans EE. Hepatitis $C$ virus screening among children exposed during pregnancy. Pediatrics 2018;141(06):e20173273

23 Rosen HR. "Hep C, where art thou": what are the remaining (fundable) questions in hepatitis $C$ virus research? Hepatology 2017;65(01):341-349

24 Lazarus JV, Wiktor S, Colombo M, Thursz M; EASL International Liver Foundation. Micro-elimination - a path to global elimination of hepatitis C. J Hepatol 2017;67(04):665-666

25 Sokal E, Nannini P. Hepatitis C virus in children: the global picture. Arch Dis Child 2017;102(07):668-671

26 Chemaitelly H, Mahmud S, Kouyoumjian SP, Al-Kanaani Z, Hermez JG, Abu-Raddad LJ. Who to test for hepatitis $C$ virus in the Middle East and North Africa?: pooled analyses of 2,500 prevalence measures, including 49 million tests Hepatol Commun 2019;3(03):325-339

27 Waddington C, Sambo C. Financing health care for adolescents: a necessary part of universal health coverage. Bull World Health Organ 2015;93(01):57-59

28 Suryaprasad AG, White JZ, Xu F, et al. Emerging epidemic of hepatitis $C$ virus infections among young nonurban persons who inject drugs in the United States, 2006-2012. Clin Infect Dis 2014; 59(10):1411-1419 
29 Zibbell JE, Iqbal K, Patel RC, et al; Centers for Disease Control and Prevention (CDC). Increases in hepatitis $C$ virus infection related to injection drug use among persons aged $£ 30$ years - Kentucky, Tennessee, Virginia, and West Virginia, 2006-2012. MMWR Morb Mortal Wkly Rep 2015;64(17):453-458

30 Benova L, Mohamoud YA, Calvert C, Abu-Raddad LJ. Vertical transmission of hepatitis $C$ virus: systematic review and metaanalysis. Clin Infect Dis 2014;59(06):765-773

31 Centers for Disease Control and Prevention (CDC). Hepatitis C virus infection among adolescents and young adults:Massachusetts, 2002-2009. MMWR Morb Mortal Wkly Rep 2011;60(17):537-541

32 Squires JE, Balistreri WF. Hepatitis $C$ virus infection in children and adolescents. Hepatol Commun 2017;1(02):87-98

33 Modin L, Arshad A, Wilkes B, et al. Epidemiology and natural history of hepatitis $C$ virus infection among children and young people. J Hepatol 2019;70(03):371-378

34 Thursz M, Fontanet A. HCV transmission in industrialized countries and resource-constrained areas. Nat Rev Gastroenterol Hepatol 2014;11(01):28-35

35 Save the Children. Complete End of Childhood Index. The Complete Face of Exclusion. Available at: https://www.savethechildren. org/content/dam/global/reports/2018-end-of-childhood-report. pdf. Accessed October 2019

36 UNICEF. Preparing for the Future of Children and Youth in Syria and the Region through Education: London One Year On. Available at: http://childrenofsyria.info/2017/04/04/preparing-for-the-futureof-children-and-youth-in-syria-and-the-region-through-education-london-one-year-on/. Accessed October 2019

37 Centers for Disease Control and Prevention. Viral Hepatitis Surveillance-United States, 2015. Atlanta, GA: U.S. Department of Health and Human Services, CDC; 2017

38 Ly KN, Jiles RB, Teshale EH, Foster MA, Pesano RL, Holmberg SD. Hepatitis $C$ virus infection among reproductive-aged women and children in the United States, 2006 to 2014. Ann Intern Med 2017;166(11):775-782

39 Spera AM, Eldin TK, Tosone G, Orlando R. Antiviral therapy for hepatitis C: has anything changed for pregnant/lactating women? World J Hepatol 2016;8(12):557-565

40 AASLD/IDSA. HCV Guidance: Recommendations for Testing, Managing, and Treating Hepatitis C. Available at: https://www.hcvguidelines.org/sites/default/files/full\%E2\%80\%90guidance\%E2\%80\%90 pdf/HCVGuidance_May_24_2018b.pdf. Accessed December 2019

41 Yattoo NG. Treatment of chronic hepatitis $C$ with ledipasvir/sofosbuvir combination during pregnancy. Presented at the 27th Annual Conference of APASL, March 14-18, 2018, New Delhi, India

42 Chappell CA, Krans EE, Bunge K, et al. A phase I study of ledipasvir/sofosbuvir in pregnant women with hepatitis $C$ virus. Presented at the Conference on Retroviruses and Opportunistic Infections, March 8-11, 2020, Boston, MA

43 El-Sayed MH, Elakel W, Elsharkawy A, et al. DAA therapy in women of child bearing age: accidental conception during therapy and pregnancy outcome. Presented at the International Liver Congress by the European Association for the Study of the Liver, April 10-14, 2019, Vienna, Austria

44 Freriksen JJM, van Seyen M, Judd A, et al. Review article: direct-acting antivirals for the treatment of HCV during pregnancy and lactation implications for maternal dosing, foetal exposure, and safety for mother and child. Aliment Pharmacol Ther 2019;50(07):738-750

45 Meites E, Szilagyi PG, Chesson HW, Unger ER, Romero JR, Markowitz LE. Human papillomavirus vaccination for adults: updated recommendations of the Advisory Committee on Immunization Practices. MMWR Morb Mortal Wkly Rep 2019;68 (32):698-702

46 Lazarus JV, Safreed-Harmon K, Thursz MR, et al. The microelimination approach to eliminating hepatitis C: strategic and operational considerations. Semin Liver Dis 2018;38(03): 181-192
47 Greenaway C, Thu Ma A, Kloda LA, et al. The seroprevalence of hepatitis $C$ antibodies in immigrants and refugees from intermediate and high endemic countries: a systematic review and meta-analysis. PLoS One 2015;10(11):e0141715

48 UNICEF. Child Refugees and Migrants. Available at: https://www. unicefusa.org/mission/emergencies/child-refugees. Accessed October 14, 2019

49 World Health Organization. Guidelines on Hepatitis B and C testing. Available at: https://apps.who.int/iris/bitstream/handle/ 10665/254621/9789241549981-eng.pdf?sequence $=1$. Accessed December 2019

50 Fernandez M, Manzanares S, Jacques C, Caylá J, Kunkel J, Foster G. Screening for chronic viral hepatitis in migrant populationsReport on Four HEPscreen Pilot Studies screening for chronic viral hepatitis in migrant populations. Available at: http:// hepscreen.eu/wp-content/uploads/2014/12/HEPscreen_FinalWP6-report_Pilot-studies.pdf. Accessed December 2019

51 Jafferbhoy H, Miller MH, McIntyre P, Dillon JF. The effectiveness of outreach testing for hepatitis $C$ in an immigrant Pakistani population. Epidemiol Infect 2012;140(06):1048-1053

52 Perumalswami PV, DeWolfe Miller F, Orabee H, et al. Hepatitis C screening beyond CDC guidelines in an Egyptian immigrant community. Liver Int 2014;34(02):253-258

53 Perumalswami PV, Factor SH, Kapelusznik L, et al. Hepatitis Outreach Network: a practical strategy for hepatitis screening with linkage to care in foreign-born communities. J Hepatol 2013;58(05):890-897

54 Zuure FR, Bouman J, Martens M, et al. Screening for hepatitis B and $C$ in first-generation Egyptian migrants living in the Netherlands. Liver Int 2013;33(05):727-738

55 Hargreaves S, Seedat F, Car J, et al. Screening for latent TB, HIV, and hepatitis $\mathrm{B} / \mathrm{C}$ in new migrants in a high prevalence area of London, UK: a cross-sectional study. BMC Infect Dis 2014;14:657

56 Bottero J, Boyd A, Gozlan J, et al. Simultaneous human immunodeficiency virus-hepatitis B-hepatitis C point-of-care tests improve outcomes in linkage-to-care: results of a randomized control trial in persons without healthcare coverage. Open Forum Infect Dis 2015;2(04):ofv162

57 Rumi MG, Di Marco V, Colombo M. Management of HCV-Related Liver Disease in Hemophilia and Thalassemia. Semin Liver Dis 2018;38(02):112-120

58 World Health Organization. Global Status Report on Blood Safety and Availability. Available at: https://apps.who.int/iris/bitstream/ handle/10665/254987/9789241565431-eng.pdf? sequence $=1$. Accessed October 18, 2019

59 Zhang M, Rosenberg PS, Brown DL, et al; Second Multicenter Hemophilia Cohort Study. Correlates of spontaneous clearance of hepatitis C virus among people with hemophilia. Blood 2006; 107(03):892-897

60 Lai ME, Origa R, Danjou F, et al. Natural history of hepatitis C in thalassemia major: a long-term prospective study. Eur J Haematol 2013;90(06):501-507

61 Katsanos KHCA, Christodoulou DK, Tzambouras N, Zervou Eleftheria Bourandas KL, Tsianos EV. Epidemiological and clinical characteristics of HCV infection in transfusion dependent thalassemia. Ann Gastroenterol 2005;18:54-56

62 Prati D, Zanella A, Farma E, et al. A multicenter prospective study on the risk of acquiring liver disease in anti-hepatitis $C$ virus negative patients affected from homozygous beta-thalassemia. Blood 1998;92(09):3460-3464

63 Jang TY, Lin PC, Huang CI, et al. Seroprevalence and clinical characteristics of viral hepatitis in transfusion-dependent thalassemia and hemophilia patients. PLoS One 2017;12(06):e0178883

64 Ahmed Kiani R, Anwar M, Waheed U, Asad MJ, Abbasi S, Abbas Zaheer H. Epidemiology of transfusion transmitted infection among patients with $\beta$-thalassaemia major in Pakistan. J Blood Transfus 2016;2016:8135649 
65 Jafroodi M, Davoudi-Kiakalayeh A, Mohtasham-Amiri Z, Pourfathollah AA, Haghbin A. Trend in prevalence of hepatitis $C$ virus infection among $\beta$-thalassemia major patients: 10 years of experience in Iran. Int J Prev Med 2015;6:89

66 Al-Naamani K, Al-Zakwani I, Al-Sinani S, Wasim F, Daar S. Prevalence of hepatitis $C$ among multi-transfused thalassaemic patients in Oman: single centre experience. Sultan Qaboos Univ Med J 2015;15(01):e46-e51

67 Chakrabarty P, Rudra S, Hossain MA. Prevalence of HBV and HCV among the multi-transfused beta thalassemic major patients in a day care centre of blood transfusion department of Mymensingh Medical College Hospital. Mymensingh Med J 2014;23(02):235-241

68 Hussein E. Evaluation of infectious disease markers in multitransfused Egyptian children with thalassemia. Ann Clin Lab Sci 2014;44(01):62-66

69 Mansour AK, Aly RM, Abdelrazek SY, et al. Prevalence of HBV and HCV infection among multi-transfused Egyptian thalassemic patients. Hematol Oncol Stem Cell Ther 2012;5(01):54-59

70 Al-Sweedan SA, Jaradat S, Amer K, Hayajneh W, Haddad H. Seroprevalence and genotyping of hepatitis $C$ virus in multiple transfused Jordanian patients with $\beta$-thalassemia major. Turk J Haematol 2011;28(01):47-51

71 Walsh CE, Workowski K, Terrault NA, et al. Ledipasvir-sofosbuvir and sofosbuvir plus ribavirin in patients with chronic hepatitis $C$ and bleeding disorders. Haemophilia 2017;23(02):198-206

72 Nagao A, Hanabusa H. Brief report: the impact of ledipasvir/ sofosbuvir on HIV-positive and HIV-negative Japanese hemophilia patients with 1, 4, and mixed-genotype HCV. J Acquir Immune Defic Syndr 2017;74(04):418-422

73 Stedman CAM, Hyland RH, Ding X, Pang PS, McHutchison JG, Gane EJ. Once daily ledipasvir/sofosbuvir fixed-dose combination with ribavirin in patients with inherited bleeding disorders and hepatitis C genotype 1 infection. Haemophilia 2016;22(02):214-217

74 Lee HW, Yoo KY, Won JW, Kim HJ. Direct acting antiviral agents in Korean patients with chronic hepatitis $C$ and hemophilia who are treatment-naïve or treatment-experienced. Gut Liver 2017; 11(05):721-727

75 Hézode C, Colombo M, Bourlière M, et al; C-EDGE IBLD Study Investigators. Elbasvir/grazoprevir for patients with hepatitis $C$ virus infection and inherited blood disorders: a phase III study. Hepatology 2017;66(03):736-745

76 Sinakos E, Kountouras D, Koskinas J, et al. Treatment of chronic hepatitis $C$ with direct-acting antivirals in patients with $\beta$ thalassaemia major and advanced liver disease. $\mathrm{Br} \mathrm{J}$ Haematol 2017;178(01):130-136

77 Mangia A, Sarli R, Gamberini R, et al. Randomised clinical trial: sofosbuvir and ledipasvir in patients with transfusion-dependent thalassaemia and HCV genotype 1 or 4 infection. Aliment Pharmacol Ther 2017;46(04):424-431

78 Origa R, Ponti ML, Filosa A, et al; Italy for THAlassemia and hepatitis C Advance - Società Italiana Talassemie ed Emoglobinopatie (ITHACA-SITE). Treatment of hepatitis $C$ virus infection with direct-acting antiviral drugs is safe and effective in patients with hemoglobinopathies. Am J Hematol 2017;92(12):1349-1355

79 Nagral A, Sawant S, Nagral N, Parikh P, Malde P, Merchant R. Generic direct acting antivirals in treatment of chronic hepatitis C infection in patients of thalassemia major. J Clin Exp Hepatol 2017;7(03):172-178

80 European Association for the Study of the Liver. EASL recommendations on treatment of hepatitis C 2016. J Hepatol 2017;66 (01):153-164

81 European Association for the Study of the Liver. EASL recommendations on treatment of hepatitis C 2018. J Hepatol 2018;69 (02):461-511

82 Indolfi G, Hierro L, Dezsofi A, et al. Treatment of chronic hepatitis $C$ virus infection in children: a position paper by the Hepatology Committee of European Society of Paediatric Gastroenterology,
Hepatology and Nutrition. J Pediatr Gastroenterol Nutr 2018;66 (03):505-515

83 Murray KF, Balistreri WF, Bansal S, et al. Safety and efficacy of ledipasvir-sofosbuvir with or without ribavirin for chronic hepatitis $C$ in children ages 6-11. Hepatology 2018;68(06):2158-2166

84 Schwarz KB, Rosenthal P, Murray KF, et al. Ledipasvir-sofosbuvir for 12 weeks in children 3 to $<6$ years old with chronic hepatitis C. Hepatology 2020;71(02):422-430

85 Balistreri WF, Murray KF, Rosenthal P, et al. The safety and effectiveness of ledipasvir-sofosbuvir in adolescents $12-17$ years old with hepatitis $C$ virus genotype 1 infection. Hepatology 2017;66(02):371-378

86 Garrison K, Mathias A, Kersey K, et al. Pharmacokinetics of once daily sofosbuvir or ledipasvir/sofosbuvir in HCV-infected pediatrics aged 6 to $<12$ years old. Paper presented at the Liver Meeting, November 11-15, 2016, Boston, MA

87 El-Khayat HR, Kamal EM, El-Sayed MH, et al. The effectiveness and safety of ledipasvir plus sofosbuvir in adolescents with chronic hepatitis $C$ virus genotype 4 infection: a real-world experience. Aliment Pharmacol Ther 2018;47(06):838-844

88 El-Karaksy H, Mogahed EA, Abdullatif H, et al. Sustained viral response in genotype 4 chronic hepatitis $C$ virus-infected children and adolescents treated with sofosbuvir/ledipasvir. J Pediatr Gastroenterol Nutr 2018;67(05):626-630

89 Dhiman RK, Grover GS, Premkumar M, et al. Direct-acting antiviral therapy is safe and effective in pediatric chronic hepatitis C: the public health perspective. J Pediatr Gastroenterol Nutr 2019;68(01):74-80

90 El-Shabrawi MHF, Kamal NM, El-Khayat HR, Kamal EM, AbdElgawad MMAH, Yakoot M. A pilot single arm observational study of sofosbuvir/ledipasvir $(200+45 \mathrm{mg})$ in 6 - to 12 - year old children. Aliment Pharmacol Ther 2018;47(12):1699-1704

91 El-Khayat H, Kamal EM, Yakoot M, et al. Effectiveness of 8-week sofosbuvir/ledipasvir in the adolescent chronic hepatitis Cinfected patients. Eur J Gastroenterol Hepatol 2019;31(08): 1004-1009

92 Serranti D, Dodi I, Nicastro E, et al. Shortened 8-week course of sofosbuvir/ledipasvir therapy in adolescents with chronic hepatitis c infection. J Pediatr Gastroenterol Nutr 2019;69(05):595-598

93 El-Sayed MH, Hassany M, El-Sayed Ebeid FS, et al. Ledipasvir/sofosbuvir for 8 weeks cures genotype 4 chronic hepatitis $C$ in non-cirrhotic children and adolescents. J Hepatol 2019;70:e221

94 Wirth S, Rosenthal P, Gonzalez-Peralta RP, et al. Sofosbuvir and ribavirin in adolescents $12-17$ years old with hepatitis $C$ virus genotype 2 or 3 infection. Hepatology 2017;66(04):1102-1110

95 Rosenthal P, Schwarz KB, Gonzalez-Peralta RP, et al. Sofosbuvir and ribavirin therapy for children aged 3 to $<12$ years with hepatitis $C$ virus genotype 2 or 3 infection. Hepatology 2020;71 (01):31-43

96 Hashmi MA, Cheema HA. Effectiveness and safety of sofosbuvir in treatment-näive children with hepatitis C infection. J Coll Physicians Surg Pak 2017;27(07):423-426

97 Leung DH, Yao BB, Viani RM, et al. ZIRCON: pharmacokinetics, safety, and efficacy of ombitasvir/paritaprevir/ritonavir \pm dasabuvir \pm ribavirin in adolescents with genotype 1 or 4 hepatitis $C$ virus infection. Presented at the 52nd Annual Meeting of the European Association for the Study of the Liver, April 19-23, 2017, Amsterdam, the Netherlands

98 Jonas MM, Squires RH, Rhee SM, et al. Pharmacokinetics, safety, and efficacy of glecaprevir/pibrentasvir in adolescents with chronic hepatitis $C$ virus: part 1 of the DORA study. Hepatology 2020;71(02):456-462

99 El-Sayed MH, Hassany M, Asem N. A pilot study for safety and efficacy of 12 weeks sofosbuvir plus daclatasvir with or without ribavirin in Egyptian adolescents with chronic hepatitis $C$ virus Infection. J Hepatol 2017;66(01):S178 
100 Yakoot M, El-Shabrawi MH, AbdElgawad MM, et al. Dual sofosbuvir/daclatasvir therapy in adolescent patients with chronic hepatitis C infection. J Pediatr Gastroenterol Nutr 2018;67(01):86-89

101 Padhi S, Maharshi S, Gupta GK, Garg K, Nijhawan S. Efficacy and safety of direct acting antiviral therapy for chronic hepatitis $C$ in thalassemic children. J Pediatr Hematol Oncol 2018;40(07):511-514

102 Abdel Ghaffar TY, El Naghi S, Abdel Gawad M, et al. Safety and efficacy of combined sofosbuvir/daclatasvir treatment of children and adolescents with chronic hepatitis $C$ genotype 4. J Viral Hepat 2019;26(02):263-270
103 El-Shabrawi MH, Abdo AM, El-Khayat HR, Yakoot M. Shortened 8 weeks course of dual sofosbuvir/daclatasvir therapy in adolescent patients, with chronic hepatitis $C$ infection. J Pediatr Gastroenterol Nutr 2018;66(03):425-427

104 Page K, Melia M, Rebecca T. Results of the First Prophylactic Hepatitis C Virus Vaccine Efficacy Trial. Presented at the IDWeek, October 2-6, 2019, Washington, DC

105 Penazzato M, Watkins M, Morin S, et al. Catalysing the development and introduction of paediatric drug formulations for children living with HIV: a new global collaborative framework for action. Lancet HIV 2018;5(05):e259-e264 